\title{
Maracujá: um alimento funcional?
}

\section{Maria Luiza Zeraik, ${ }^{1}$ Cíntia A. M. Pereira, ${ }^{2}$ Vânia G. Zuin, ${ }^{3}$ Janete H. Yariwake ${ }^{* 1}$}

\author{
${ }^{1}$ Instituto de Química de São Carlos, Universidade de São Paulo, Caixa Postal 780, 13560-970 São Carlos, \\ SP, Brasil \\ ${ }^{2}$ Centro Universitário Central Paulista, R. Miguel Petroni, 5111, 13563-470 São Carlos, SP, Brasil \\ ${ }^{3}$ Departamento de Metodologia de Ensino, Universidade Federal de São Carlos, Caixa Postal 676, 13565-905 \\ São Carlos, SP, Brasil.
}

\begin{abstract}
RESUMO: Este artigo é uma revisão bibliográfica sobre as espécies brasileiras de Passiflora (Passiflora edulis fo. flavicarpa O. Deg., P. alata Curtis e P. edulis fo. edulis). A maioria dos artigos da literatura focaliza somente as folhas de Passiflora, enquanto que esta revisão contém informações sobre a polpa, cascas e sementes dos frutos do maracujá, com destaque para a composição química, estudos nutricionais e farmacológicos. O enfoque nos frutos do maracujá fundamenta-se no amplo consumo do suco de maracujá (fresco ou industrializado) no Brasil e também nas investigações em andamento para avaliar o seu potencial uso como alimento funcional.
\end{abstract}

Unitermos: Passiflora, composição química, alimento funcional.

ABSTRACT: "Passion fruit: a functional food?" This paper consists of a bibliographic review of the most relevant edible Brazilian Passiflora species (Passiflora edulis fo. flavicarpa O. Deg., P. alata Curtis and P. edulis fo. edulis). Most of the reports in the literature focus solely on Passiflora leaves, whereas this review contains information about passion fruit pulp, rind and seeds, highlightening chemical composition, nutritional and pharmacological studies. The emphasis on the "maracujá" fruit is due to the extensive consumption of passion fruit juice (fresh or processed) in Brazil and on ongoing investigations into its potential as a functional food.

Keywords: Passiflora, chemical composition, functional food.

\section{INTRODUÇ̃̃O}

Maracujá, nome popular dado a várias espécies do gênero Passiflora (o maior da família Passifloraceae), vem de maraú-ya, que para os indígenas significa "fruto de sorver" ou "polpa que se toma de sorvo" (ITAL, 1994). Cerca de $90 \%$ das 400 espécies deste gênero são originárias das regiões tropicais e subtropicais do globo, sendo o maior foco de distribuição geográfica o Centro-Norte do Brasil, onde encontram-se pelo menos 79 espécies. As espécies de maior interesse comercial no país são $P$. edulis fo. Alavicarpa O. Deg., P. alata Curtis e P. edulis fo. edulis (Ruggiero, 1987).

O maracujá-azedo ou amarelo ( $P$. edulis fo. flavicarpa) é o mais cultivado e comercializado no país devido à qualidade de seus frutos. O Brasil é o maior produtor mundial de maracujá; segundo o IBGE (2007) a produção brasileira de maracujá em 2007 foi de 664.286 toneladas, com 47.032 ha de área plantada ou destinada à colheita, concentrada nos estados do Pará, Bahia, Sergipe e São Paulo. O maracujá-roxo ( $P$. edulis fo. edulis) pode ser consumido em suco ou como fruta fresca. No Brasil, o consumo de sucos de frutas, frescos ou industrializados, já é um hábito consolidado e em 2003 o consumo do suco de maracujá representou quase $25 \%$ dentre o total de 579 mil litros de sucos de frutas integrais industrializados (Pinheiro et al., 2006). Os frutos do maracujá-roxo são globosos, com 4 a $5 \mathrm{~cm}$ de diâmetro. A casca é verde antes da maturação, tornando-se púrpura após iniciado o processo. É muito apreciado na Austrália e na África do Sul e desenvolve-se em regiões de clima mais ameno e de elevadas altitudes. O maracujá amarelo apresenta uma série de características consideradas superiores ao maracujá roxo, tais como: maior tamanho do fruto, peso, teor de caroteno, acidez total, resistência a pragas e maior produtividade por hectare (Carvalho-Okano et al., 2001; Zibadi \& Watson, 2004).

Já o maracujá-doce ( $P$. alata Curtis) tem sua produção e comercialização restritas: embora originária do Brasil, é uma fruta ainda pouco conhecida pela maioria da população. Ao contrário do maracujá amarelo, é consumida exclusivamente como fruta fresca, devido à sua baixa acidez. Os frutos são ovais ou periformes, e a casca da P. alata é intensamente alaranjada, lembrando um mamão papaia. A polpa é adocicada, odor forte e agradável, mas enjoativa quando utilizada na forma de suco (Meletti, 
1996).

Os medicamentos fitoterápicos à base de maracujá devem ser elaborados a partir das espécies $P$. alata e $P$. incarnata, espécies oficiais da Farmacopeia Brasileira (1977) e Europeia (1996), respectivamente. Ao investigar o perfil de utilização de fitoterápicos pela população brasileira, alguns autores evidenciaram que Passiflora está entre os mais utilizados (Marliére et al., 2008; Silva et al., 2006; Ribeiro et al., 2005).

A partir da década de 90 do século passado, houve valorização do preço da fruta fresca, e atualmente quase toda a produção de frutas frescas é destinada ao mercado interno, enquanto que menos da metade do volume de frutas processadas, essencialmente na forma de suco concentrado, é voltado ao mercado brasileiro (Meletti \& Maia, 1999). Além disso, existe a pressão do mercado devido às doenças, em especial o PWV (Passion fruit Woodeness Virus), conhecido popularmente como o "vírus do endurecimento dos frutos". Este vírus é transmitido por pulgões e causa redução quantitativa e qualitativa na produção, pois os frutos ficam menores, deformados e endurecidos, podendo até exibir rachaduras, dependendo da estirpe do vírus (Gioria et al., 2000). Antes de ocorrerem as frequentes epidemias, a cultura era perene e por pelo menos três anos consecutivos, mas em decorrência principalmente do PWV, o cultivo está tornando-se anual (Sampaio et al., 2008).

Os produtos registrados no Ministério da Agricultura para o controle químico de pragas e doenças em culturas de maracujá nem sempre possibilitam resultados satisfatórios. Assim, alguns produtos utilizados atualmente para o tratamento fitossanitário do maracujá não estão registrados no Ministério da Agricultura (2010), tais como: benomil, paration, dentre outros (Zuin et al., 2003). Porém, quando solicitado pela Secretária da Agricultura em caráter excepcional, alguns destes produtos podem ser legalmente empregados após a autorização de uso emergencial concedida pelo Governo Federal (Cati, 1992).

\section{Maracujá: um alimento funcional?}

Vários estudos indicam a presença de substâncias polifenólicas (Zeraik \& Yariwake, 2010), ácidos graxos poliinsaturados (Kobori \& Jorge, 2005) e fibras (Córdova et al., 2005), entre outras classes de substâncias, e a existência destas substâncias no fruto pode indicar o potencial do maracujá como um alimento funcional.

Nos últimos anos tem-se atribuído aos alimentos, além das funções de nutrição e de prover apelo sensorial, uma terceira função relacionada à resposta fisiológica específica produzida por alguns alimentos, que são chamados de alimentos funcionais. Estes alimentos podem prevenir, curar ou auxiliar na recuperação de determinadas doenças (Culhane, 1995). Os alimentos funcionais fazem parte de uma recente concepção de alimentos, lançada pelo
Japão na década de 80 , através de um programa de governo que tinha como objetivo desenvolver alimentos saudáveis para uma população que envelhecia e apresentava uma grande expectativa de vida (Anjo, 2004).

O termo "alimento funcional" é tema de estudo e discussão por muitos autores (Lajolo, 2001; Angelis, 2001; Araújo, 2005; Moraes \& Colla, 2006). Um alimento pode ser considerado funcional se for demonstrado que o mesmo pode afetar beneficamente uma ou mais funções alvo no corpo, além de possuir efeitos nutricionais adequados, de maneira que seja tanto relevante para o bem estar e a saúde quanto para a redução do risco de uma doença (Roberfroid, 2002). Não são considerados medicamentos, pois os princípios responsáveis pelos efeitos benéficos não são extraídos do alimento (Costa \& Tupinambá, 2005).

Frutas e vegetais contêm substâncias com efeito protetor, e estudos in vitro e in vivo mostram que estas substâncias protetoras podem inibir vários estágios do processo de carcinogênese (Hollman \& Katan, 1997). Entre os diversos tipos de alimentos funcionais, destacam-se os que contêm substâncias antioxidantes, como a vitamina $C$, vitamina E, carotenoides e flavonoides (Hollman \& Katan, 1999).

\section{FARMACOLOGIA}

Pereira \& Vilegas (2000) realizaram uma revisão sobre a farmacologia, toxicologia e constituintes químicos presentes nas folhas das espécies: P. alata, P. edulis fo. flavicarpa, P. edulis fo. edulis e P. incarnata. Uma vasta revisão também foi realizada por Dhawan et al. (2004), descrevendo a ação farmacológica, toxicologia e os constituintes químicos das folhas de várias espécies do gênero Passiflora. O gênero também é citado na revisão de Sousa et al. (2008) sobre plantas utilizadas nos distúrbios da ansiedade. Assim, este artigo tem como objetivo central os estudos relacionados aos frutos, cascas e sementes das espécies de Passiflora mais cultivadas no Brasil: P. edulis fo. Alavicarpa, P. edulis fo. edulis e P. alata, coletandose dados da literatura de 1950 a 2008 com ênfase aos estudos farmacológicos e nutricionais, e aos principais constituintes químicos destas três espécies. O levantamento bibliográfico foi realizado utilizando-se as seguintes bases de dados: Scopus, Web of Science e Scienfinder Scholar.

\section{Frutos}

Várias pesquisas têm sido conduzidas mostrando o potencial do maracujá (fruto, casca e semente) para várias finalidades, e a atividade biológica mais estudada com relação aos frutos do maracujá é sua ação antioxidante. A atividade antioxidante em sucos é atribuída aos polifenóis, principalmente aos flavonoides (Heim et al., 2002).

Kuskoski et al. (2006) determinaram a atividade antioxidante em várias polpas de frutas tropicais, entre elas o maracujá, utilizando o método do radical 2,2-difenil-1- 
picrilhidrazil (DPPH), encontrando um valor de 1,02 $\pm 0,4$ $\mu \mathrm{mol} \mathrm{g}^{-1}$, valor expresso em atividade antioxidante equivalente ao Trolox após $60 \mathrm{~min}$ de reação. Também foram determinados os polifenóis totais pelo método de Folin-Ciocalteu $\left(20,0 \pm 2,6 \mathrm{mg} 100 \mathrm{~g}^{-1}\right)$ e a quantidade de antocianinas, pelo método da diferença de $\mathrm{pH}$; porém não foram encontradas antocianinas na polpa do fruto. Em trabalho anterior Kuskoski et al. (2005) realizaram a comparação de diferentes métodos espectrofotométricos para determinação da atividade antioxidante, encontrando resultado similar utilizando os métodos ABTS (ácido 2,2'-azino-bis (3-etilbenzotiazolin)-6-sulfônico) e $\mathrm{DPPH}$, sendo as vantagens deste último a rapidez (1 minuto) e resultados reprodutíveis e com maior exatidão, diferentemente do método DMPD (dicloridrato de $N, N$ dimetil- $p$-fenilendiamina).

Vasco et al. (2008) estudaram a atividade antioxidante das principais frutas do Equador, dentre elas o maracujá ( $P$. edulis fo. flavicarpa), usando três diferentes métodos: DPPH, FRAP (poder antioxidante de redução do ferro) e ABTS. Os autores verificaram baixo nível de substâncias fenólicas $(61 \pm 32 \mathrm{mg}$ expressos em equivalente de ácido gálico/100 g de amostra), mas forte capacidade antioxidante $(0,5 \pm 0,3 \mu \mathrm{mol}$ Trolox/g de amostra). Foram analisados a quantidade de ácido ascórbico (30-40 $\mathrm{mg} / 100 \mathrm{~g}$ de amostra) e o teor total de polifenóis solúveis (61 $\pm 32 \mathrm{mg}$ de ácido gálico equivalente/100g de amostra), resultado considerado baixo pelo autor $(<100 \mathrm{mg}$ ácido gálico equivalente/100 $\mathrm{g}$ de amostra).

Zeraik et al. (2008) avaliaram a atividade antioxidante da polpa de maracujá, em comparação com a garapa e o chá-mate pelo método do DPPH, e foi observado que a capacidade antioxidante das amostras seguiu a seguinte ordem: rutina $>$ resveratrol $>$ chá-mate $>$ polpa do maracujá>garapa. Os resultados do método do DPPH foram comparados com o método CRAC (capacidade antioxidante de redução do cério) (Ferreira \& Avaca, 2008).

Zucolotto (2005) investigou o extrato aquoso liofilizado do pericarpo dos frutos e das raízes de $P$. edulis fo. Alavicarpa, que apresentaram atividade anti-inflamatória moderada utilizando o modelo da pleurisia induzida pela carregenina, em camundongos.

Puricelli et al. (2003) verificaram que o decocto do fruto de $P$. edulis (variedade não especificada) inibiu in vitro a atividade da matriz-metaloproteinase- 2 e a matrizmetaloproteinase-9, duas gelatinases envolvidas na invasão tumoral, metástases e angiogeneses. A atividade inibitória foi mais eficiente para matriz-metaloproteinase-2.

Apenas um estudo foi encontrado com relação ao possível efeito ansiolítico do suco de maracujá. Lutomski et al. (1975) estudando os efeitos em camundongos dos sucos do fruto de $P$. edulis (variedade não especificada) e $P$. edulis fo. flavicarpa, verificaram efeito tranquilizante por via oral, com diminuição significativa da movimentação espontânea dos animais, o que foi atribuído à presença de pequenas quantidades de alcaloides harmânicos e de flavonoides.

Araújo et al. (2004) avaliaram a atividade biológica de proteínas totais presentes em várias polpas de frutos tropicais, e a polpa do maracujá apresentou a maior quantidade de proteínas $(0,8 \mathrm{mg}$ de proteínas/g de polpa) entre as amostras testadas, porém não mostrou atividade inibidora de enzimas digestivas mamíferas.

Não foram encontrados estudos sobre os constituintes químicos e a farmacologia dos frutos de $P$. alata.

\section{Cascas}

De acordo com Oliveira et al. (2002) os subprodutos (cascas e sementes) produzidos no processamento do suco do maracujá correspondem a cerca de 65 a $70 \%$ do peso do fruto, sendo portanto um grande problema de resíduo agroindustrial. A utilização destes subprodutos na alimentação humana ou animal como fonte alimentar de bom valor nutricional mostra-se viável, reduzindo custos e, ao mesmo tempo, diminuindo os problemas de eliminação dos subprodutos provenientes do processamento. A casca de maracujá é rica em fibras solúveis, principalmente pectina, que é benéfica ao ser humano (Guertzenstein, 1998; Yapo \& Koffi, 2006). Ao contrário da fibra insolúvel (contida no farelo dos cereais), que pode interferir na absorção do ferro, a fibra solúvel pode auxiliar na prevenção de doenças cardiovasculares e gastrointestinais, câncer de colón, hiperlipidemias, diabetes e obesidade, entre outras (Schweize \& Wursch, 1991; Turano et al., 2002).

A casca do maracujá é também rica em niacina (vitamina B3), ferro, cálcio, e fósforo (Tabela 1) (Gondim et al., 2005), e as cascas já foram testadas e usadas com sucesso na alimentação animal (Otagaki \& Matsumoto, 1958; Togashi et al., 2007). Paiva (1998) demonstrou que o emprego dos resíduos industriais do maracujá (cascas e sementes) na alimentação de bovinos levam os animais a produzirem mais leite, inibindo inclusive problemas digestivos. Foram também verificados os benefícios da farinha de casca de maracujá como redutor da glicemia (no controle de diabetes) (Guertzentein \& Sabaa-Srur, 1999).

Ramos (2004) constatou que o extrato seco da casca de maracujá amarelo exerce uma ação positiva sobre o controle glicêmico no tratamento do diabete mellitus tipo II, sendo o provável mecanismo desta ação a presença de um alto teor de pectina, totalmente degradável no organismo, que ajuda a diminuir a taxa de glicose e colesterol no sangue, sugerindo o uso do extrato seco da casca do maracujá como adjuvante das terapias convencionais. Agra et al. (2007), em extenso levantamento sobre as plantas medicinais mais utilizadas no nordeste brasileiro, evidenciaram que o mesocarpo seco e pulverizado de $P$. edulis (variedade não especificada) é utilizado popularmente contra o diabetes. Ramos et al. (2007) observaram por meio de um estudo 
clínico piloto que o tratamento com a farinha da casca do maracujá ( $P$. edulis fo. flavicarpa) resultou na diminuição dos níveis de colesterol em mulheres entre 30 e 60 anos que apresentavam hipercolesterolemia (colesterol $\geq 200$ $\mathrm{mg} / \mathrm{dL})$.

Ichimura et al. (2006) demonstraram o efeito anti-hipertensivo do extrato metanólico da casca de P. edulis (variedade não especificada) em ratos naturalmente hipertensos. Este efeito foi atribuído principalmente ao ácido $\gamma$-aminobutirico (GABA) e parcialmente à ação vasodilatadora dos polifenóis, principalmente da luteolina (8).

Zibadi et al. (2007) investigaram o efeito antihipertensivo do extrato da casca de maracujá roxo (mistura de bioflavonoides, ácidos fenólicos e antocianinas) em ratas e em mulheres naturalmente hipertensas. No modelo experimental, 24 ratas naturalmente hipertensas foram divididas em três grupos por um período de oito semanas: um grupo controle e dois grupos alimentados com dieta suplementada com 10 ou $50 \mathrm{mg} / \mathrm{kg}$ de extrato de cascas de maracujá roxo. Já no experimento com mulheres naturalmente hipertensas foram administrados extratos de cascas de maracujá roxo em um grupo $(400 \mathrm{mg} / \mathrm{d})$, enquanto que pílulas placebo foram aplicadas em outro grupo por quatro semanas, para posterior comparação. $\mathrm{O}$ efeito dos extratos nas mulheres e ratas naturalmente hipertensas foi avaliado por meio da medida da pressão sanguínea. Observou-se diminuição significativa na pressão sanguínea em ambos os experimentos, sendo que os pacientes não apresentaram nenhum efeito colateral, sugerindo que o extrato possa ser uma alternativa segura no tratamento de hipertensão.

Watson et al. (2008) estudaram pacientes com asma durante quatro semanas, administrando extratos de cascas de maracujá roxo ou pílulas placebo, para posterior comparação. Os efeitos dos extratos foram avaliados por meio dos sintomas clínicos da asma e testes espirométricos. Os autores constataram que o extrato da casca do maracujá roxo, administrado por via oral em seres humanos, melhorou os sintomas clínicos da asma, como, diminuição do chiado no peito e tosse e causou uma melhora em relação à falta de ar, os pacientes não apresentaram efeitos colaterais.

\section{Sementes}

As sementes do maracujá são consideradas boas fontes de ácidos graxos essenciais que podem ser utilizados nas indústrias alimentícias e cosméticas. $O$ ácido linoleico ( $\omega-6)$ é um dos principais ácidos graxos do óleo da semente de maracujá (cerca de 55-66\%), seguido pelo ácido oleico (18-20\%) e do ácido palmítico (10$14 \%)$. Já o ácido linolênico ( $\omega-3)$ é encontrado em menor quantidade (0,8-1\%) (Leonel et al., 2000). Os ácidos graxos poliinsaturados $\omega-3$ e $\omega-6$ desempenham importantes funções na manutenção das membranas celulares, funções cerebrais e da transmissão de impulsos nervosos (Martin et al., 2006).

Ferrari et al. (2004) constataram que o óleo extraído das sementes de maracujá possui elevado teor de ácidos graxos insaturados $(87,54 \%)$, demonstrando que este produto tem um bom potencial para aproveitamento tanto na alimentação humana e animal quanto no uso para a indústria de cosméticos. Também verificou-se que o farelo desengordurado obtido após a moagem das sementes e extração com hexano apresentou significativo teor proteico e de fibras.

Chau \& Huang (2005) mostraram que hamsters alimentados com fibras obtidas de sementes de $P$. edulis (variedade não especificada) apresentaram redução significativa nos níveis de triglicerídeos, colesterol total e no fígado e tiveram aumento de lipídeos e de ácido biliares nas fezes, indicando que as fibras do maracujá podem ter propriedade hipocolesterolêmica na alimentação humana.

Tabela 1. Teor de nutrientes em cascas in natura de maracujá amarelo (P. edulis fo. flavicarpa) (Gondim et al., 2005).

\begin{tabular}{lc}
\hline \multicolumn{1}{c}{ Parâmetros } & Quantidades em $100 \mathrm{~g}$ de cascas \\
\hline Umidade & $87,64 \mathrm{~g}$ \\
Cinzas & $0,57 \mathrm{~g}$ \\
Lipídeos & $0,01 \mathrm{~g}$ \\
Proteínas & $0,67 \mathrm{~g}$ \\
Fibras & $4,33 \mathrm{~g}$ \\
Carboidratos & $6,78 \mathrm{~g}$ \\
Calorias & $29,91 \mathrm{kcal}$ \\
Cálcio & $44,51 \mathrm{mg}$ \\
Ferro & $0,89 \mathrm{mg}$ \\
Sódio & $43,77 \mathrm{mg}$ \\
Magnésio & $27,82 \mathrm{mg}$ \\
Zinco & $0,32 \mathrm{mg}$ \\
Cobre & $0,04 \mathrm{mg}$ \\
Potássio & $178,40 \mathrm{mg}$ \\
\hline
\end{tabular}

\section{TOXICOLOGIA}

Os aspectos toxicológicos do maracujá têm sido estudados principalmente quanto à presença de glicosídeos cianogênicos, substâncias que produzem ácido cianídrico (HCN) como um dos produtos da sua hidrólise. A cianogênese ocorre por ação de enzimas ( $\beta$-glucosidases), presentes em outro compartimento celular das plantas: quando a compartimentalização é rompida, a enzima e o substrato entram em contato e ocorre a cianogênese, sugerindo ser uma defesa química frente às injúrias (Robbers et al., 1996).

Os glicosídeos cianogênicos descritos em espécies de Passiflora tipicamente apresentam estruturas com anéis de cinco membros, como $p$. ex., a prunasina, encontrada nas folhas de $P$. edulis fo. edulis e nos frutos de P. edulis fo. flavicarpa (Spencer \& Seigler, 1983; Spencer 
et al., 1986).

Spencer \& Seigler (1983) encontraram quantidades significativas de glicosídeos cianogênicos em todas as partes das duas espécies de P. edulis, exceto nas sementes. Comparando-se os frutos do maracujá amarelo e roxo (Tabela 2), observou-se que frutos de $P$. edulis fo. flavicarpa apresentaram níveis subtóxicos até três vezes maiores $(59,40 \mathrm{mg}$ de $\mathrm{HCN} / 100 \mathrm{~g}$ no fruto verde) que o valor considerado tóxico ( $20 \mathrm{mg}$ de $\mathrm{HCN} / 100 \mathrm{~g}$ de material fresco).

Tabela 2. Valores médios de $\mathrm{HCN}$ e prunasina encontrados no maracujá (Spencer\& Seigler, 1983).

\begin{tabular}{lccc}
\hline \multicolumn{1}{c}{ Estágio } & $\begin{array}{c}\text { mg HCN/100g } \\
\text { de material } \\
\text { fresco }\end{array}$ & HCN (\%) & $\begin{array}{c}\text { Prunasina } \\
(\%)\end{array}$ \\
\hline \multicolumn{4}{c}{ Maracujá-roxo (P. edulis Sims.) } \\
\hline Frutos verdes & 13,300 & 0,013 & 0,140 \\
Frutos meio verdes & 10,500 & 0,010 & 0,011 \\
Frutos maduros no pé & 10,000 & 0,010 & 0,011 \\
\hline \multicolumn{4}{c}{ Maracujá-amarelo (P. edulis fo. flavicarpa) } \\
\hline Frutos verde & 59,400 & 0,059 & 0,650 \\
Frutos meio verdes & 15,900 & 0,016 & 0,170 \\
Frutos maduros no pé & 14,600 & 0,015 & 0,160 \\
Frutos maduros no chão & 6,500 & 0,006 & 0,070 \\
\hline
\end{tabular}

Chassagne et al. (1996a) relatam a prunasina como glicosídeo cianogênico majoritário nas cascas (287 $\mathrm{mg} / \mathrm{kg}$ em P. edulis fo. Alavicarpa e $231 \mathrm{mg} / \mathrm{kg}$ em P. edulis fo. edulis). No suco foram encontrados amigdalina $(31 \mathrm{mg} /$ $\mathrm{kg}$ em P. edulis fo. flavicarpa e $14 \mathrm{mg} / \mathrm{kg} \mathrm{em} \mathrm{P.} \mathrm{edulis} \mathrm{fo.}$ edulis) e duas substâncias tentativamente identificadas como mandelonitrila ramnopiranosil- $\beta$-D-glucopiranosídeos (99 $\mathrm{mg} / \mathrm{kg}$ em P. edulis fo. flavicarpa e $40 \mathrm{mg} / \mathrm{kg}$ em P. edulis fo. edulis). Diferentes quantidades de sambunigrina foram encontradas nos suco e nas cascas ( $3,2 \mathrm{mg} / \mathrm{kg}$ no suco e 15,7 $\mathrm{mg} / \mathrm{kg}$ na casca de $P$. edulis fo. Alavicarpa). Chassagne \& Crouzet (1998) também isolaram o glicosídeo cianogênico $\beta$-rutinosídeo (R-mandelonitrila $\alpha$-L-ramnopiranosil- $\beta$-Dglucopiranosídeo) do suco do maracujá roxo, e a estrutura foi elucidada principalmente por hidrólise enzimática e por análise por CG-EM (cromatografia gasosa acoplada à espectrometria de massas) e RMN (ressonância magnética nuclear).

De acordo com Morton (1987) os glicosídeos cianogênicos são encontrados na polpa dos diversos tipos de maracujás em todos os estágios do desenvolvimento, mas em maior quantidade na planta jovem e com frutos verdes, diminuindo com o crescimento da planta e não apresentando significância toxicológica.

PROPRIEDADES ALIMENTÍCIAS DO SUCO, CASCA E SEMENTE DE MARACUJÁ: CONSTITUINTES QUÍMICOS

\section{Açúcares e fibras}

O teor de açúcares no suco de maracujá das variedades amarela e roxa foi determinado por Chan \& Kwok (1975) utilizando CG e derivatização, e foram encontradas concentrações similares de frutose, D-glucose e sucrose nos sucos das duas variedades (Tabela 3). Segundo Haard \& Chism (1996), estes açúcares são os mais comumente encontrados em frutas.

Tabela 3. Composição nutricional em $100 \mathrm{~g}$ de fruta fresca.

\begin{tabular}{|c|c|c|}
\hline Componentes & $\begin{array}{l}\text { P.edulis f. } \\
\text { flavicarpa }^{1}\end{array}$ & P. edulis ${ }^{2}$ \\
\hline Umidade (\%) & 72,20 & 75,10 \\
\hline Proteínas (g) & 3,00 & 2,20 \\
\hline Gordura (g) & 0,12 & 0,70 \\
\hline Glucose $(\%)^{3}$ & 38,10 & 37,10 \\
\hline Frutose $(\%)^{3}$ & 29,40 & 33,50 \\
\hline Sucrose $(\%)^{3}$ & 32,40 & 29,40 \\
\hline Fibras (\%) & 12,80 & 0,04 \\
\hline Ácido cítrico (meq) ${ }^{3}$ & 13,10 & 55,00 \\
\hline Ácido málico $(\mathrm{meq})^{3}$ & 10,55 & 3,86 \\
\hline Ácido lático (meq) ${ }^{3}$ & 0,58 & 7,49 \\
\hline Ácido malônico (meq) ${ }^{3}$ & 0,13 & 4,95 \\
\hline Ácido succínico $(\mathrm{meq})^{3}$ & Traços & 2,42 \\
\hline Cinzas (\%) & 0,50 & 0,80 \\
\hline Sódio (mg) & 8,00 & 28,00 \\
\hline Potássio (mg) & 208,00 & 348,00 \\
\hline Cálcio (mg) & 6,80 & 13,00 \\
\hline Ferro (mg) & 0,60 & 1,60 \\
\hline Fósforo (mg) & 63,80 & 64,00 \\
\hline Magnésio (mg) & 28,004 & $17,00^{5}$ \\
\hline Zinco (mg) & 0,604 & $0,10^{5}$ \\
\hline Cobre (mg) & 0,194 & $0,10^{5}$ \\
\hline Vitamina A (U.I) & 200,00 & 700,00 \\
\hline Tiamina (mg) & Traços & Traços \\
\hline Riboflavina (mg) & 0,10 & 0,10 \\
\hline Niacina (mg) & $1,50-2,20$ & 1,50 \\
\hline Ácido ascórbico (mg) & 22,00 & 30,00 \\
\hline
\end{tabular}

${ }^{1}$ Romero-Rodriguez et al. (1994); ${ }^{2}$ Morton (1987); ${ }^{3}$ Chan et al., (1972); ${ }^{4}$ Kidøy et al. (1997); ${ }^{5}$ Zibadi \& Watson (2004).

Chau \& Huang (2004) verificaram que as sementes cruas de $P$. edulis (variedade não especificada) são ricas em lipídeos, fibras dietéticas insolúveis, contendo pequena quantidade de fibras dietéticas solúveis, proteínas, cinzas e carboidratos. Foram também encontrados os monossacarídeos: ramnose, fucose, arabinose, xilose, manose, galactose, glucose não celulósica, glucose celulósica e ácido urônico, sendo que a arabinose (açúcar da substância pectina) foi o principal polissacarídeo 
encontrado. A quantificação destes monossacarídeos foi realizada por $\mathrm{CG}$.

Na casca de $P$. edulis fo. flavicarpa foi encontrado um alto teor de fibra bruta (base úmida) e também de fibra alimentar total (base seca) (Córdova et al., 2005).

\section{Ácidos orgânicos}

Ácidos não voláteis foram detectados no suco de maracujá da variedade roxa e amarela por Chan et al. (1972) utilizando colunas de troca iônica para a separação, CCD (cromatografia em camada delgada) e CG para a identificação. Foram encontrados os ácidos cítrico, málico e lático, além de, em menores proporções, os ácidos malônico, succínico, ascórbico e galacturônico. Tanto a variedade roxa quanto a amarela são ácidas ( $\mathrm{pH}$ dos sucos aproximadamente 3,0). A razão açúcar/ácido é, algumas vezes, usada como medida de doçura e há pequenas diferenças nas variedades: 5:1 na roxa comparada a 3:8 na amarela; desta forma a variedade roxa é geralmente considerada mais doce.

Sobre a composição do óleo das sementes de maracujá ( $P$. edulis fo. flavicarpa), Kobori \& Jorge (2005) encontraram de 22 a $28 \%$ de óleo e como ácidos graxos mais importantes: ácido linoleico (55-66\%), oleico (18-20\%) e palmítico (10-14\%), também encontrando aproximadamente $7 \%$ de ácidos graxos livres. Schieber et al. (2001) verificou a presença de $65 \%$ de ácido linoleico no óleo das sementes desta espécie.

Ferrari et al. (2004) caracterizaram o óleo do farelo das sementes de $P$. edulis fo. flavicarpa por meio da metodologia oficial da AOCS (American Oil Chemists Society), e o farelo desengordurado obtido foi caracterizado por métodos físico-químicos através da metodologia oficial da AOAC (Association of Official Analytical Chemists). O óleo extraído das sementes apresentou elevado teor de ácidos graxos insaturados $(87,54 \%)$, com predominância do ácido linoleico $(68,79 \%)$. Foram encontrados também os ácidos mirístico $(0,08 \%)$, palmítico $(12,04 \%)$, estereático (traços), oleico $(18,06 \%)$ e linolênico $(0,69 \%)$.

Piombo et al. (2006) estudaram as sementes de P. edulis f. flavicarpa, encontrando $73,4 \%$ de $\omega-6$ ácido linoleico, $209 \pm 8,0 \mathrm{mg} / 100 \mathrm{~g}$ de fitoesteróis totais, incluindo campesterol, estigmasterol, $\beta$-sitosterol e $\delta-5$ avenasterol, $465 \pm 8,4 \mu \mathrm{g} / \mathrm{g}$ de tocoferois totais, incluindo $\alpha$-tocoferol, $\beta$-tocoferol, $\gamma$-tocoferol e $\delta$-tocoferol, justificando o uso do óleo de maracujá nas indústrias alimentícia e cosmética.

Giuffré (2007) investigou a composição química do óleo da semente do maracujá roxo ( $P$. edulis fo. edulis), analisando por CG esteróis, álcoois alifáticos e ácidos graxos. Os três principais esteróis encontrados foram $\beta$-sitosterol (42,51\%), estigmasterol (30,87\%) e campesterol $(11,14 \%)$. Os álcoois alifáticos totais no óleo foram $8,72 \mathrm{mg} / \mathrm{kg}$. Ácidos graxos poliinsaturados foram $72,60 \%$ do total, principalmente ácido linoleico $(72,26 \%)$ e ácido oleico $(16,05 \%)$.

\section{Aminoácidos}

Inomata et al. (1983) afirmam que a alanina é um componente razoavelmente constante e específico no maracujá, com teor médio de $27 \mathrm{mg} / 100 \mathrm{~mL}$ de suco. Foram encontrados os aminoácidos livres: cistina (2,9\%), lisina, taurina, histidina, arginina, asparagina (2,9\%), glicina, ácido aspártico, serina (32,0\%), ácido glutâmico, treonina $(30,4 \%)$, alanina, prolina $(23,0 \%)$, tirosina, triptofano $(3,3 \%)$, fenilalanina, metionina, valina $(3,0 \%)$, leucina, isoleucina $(2,5 \%)$.

Segundo Haard \& Chism (1996), aminoácidos livres provavelmente contribuem para o sabor das frutas, podendo ser precursores de aroma.

\section{Carotenóides}

A cor amarela intensa do suco de maracujá devese aos pigmentos carotenoides. Leuenberger \& Thommen (1972) em um estudo cromatográfico qualitativo identificaram os carotenoides da variedade roxa: $\alpha$-caroteno, $\gamma$-caroteno, fitoflueno, $\beta$-apo-12'carotenal, $\beta$-apo8 'carotenal, criptoxantina, auroxantina e mutatoxantina. Mercadante et al. (1998) identificaram treze carotenoides do maracujá amarelo: $\zeta$-caroteno (principal carotenoide), fitoeno, fitoflueno, neurosporeno, $\beta$-caroteno, licopeno, pró-licopeno, monoepóxi- $\beta$-caroteno, $\beta$-criptoxantina, $\beta$-citraurina, anteraxantina, violaxantina e neoxantina. Para a identificação foram utilizadas técnicas espectroscópicas (EM, UV-Vis, RMN ${ }^{1} \mathrm{H}$ e ${ }^{13} \mathrm{C}$ ) e cromatográficas (CCD e CLAE- cromatografia líquida de alta eficiência).

O principal papel dos carotenoides na dieta humana é de serem precursores de vitamina A. Poucos carotenoides possuem esta atividade vitamínica, que é atribuída à estrutura retinoide (com anel $\beta$-ionona). O $\beta$-caroteno é o que possui maior atividade como próvitamina A. Os carotenoides pró-vitamínicos presentes em frutas e vegetais atuam como antioxidantes na prevenção do câncer, catarata, arteriosclerose e processos de envelhecimento em geral (Von Elbe \& Schwartz, 1996; Barbosa-Filho et al., 2008).

Recentemente tem aumentado o interesse na presença de cis-carotenoides na dieta, pois a atividade próvitamina A do isômero cis é de 13 a 53\% maior quando comparada ao trans- $\beta$-caroteno (Von Elbe \& Schwartz, 1996). Godoy \& Rodriguez-Amaya (1994) verificaram que no maracujá amarelo o trans- $\beta$-caroteno é a principal pró-vitamina $(4,7 \mu \mathrm{g} / \mathrm{g})$, não sendo detectado isômeros cis. $\mathrm{O}$ valor de vitamina $\mathrm{A}$ foi de 78 equivalente de retinol/100 $\mathrm{g}$ da polpa da fruta, sem a separação de isômeros.

Sepúlveda et al. (1996) observaram que existem diferenças na cor do suco de $P$. edulis (variedade não especificada) em diferentes épocas de colheita. Observouse que o conteúdo de carotenoides na colheita de inverno é mais alto do que no verão, gerando, portanto, sucos com cor mais intensa. Os frutos colhidos no inverno apresentam 
menor teor de sólidos solúveis e maior acidez do que os colhidos no verão. Estes fatores podem influenciar na síntese dos carotenoides, provocando variações na cor dos sucos provenientes de períodos distintos de colheita. As características de cor, sólidos solúveis e a acidez são fatores determinantes para a utilização do fruto em processos industriais.

\section{Antocianinas}

No gênero Passiflora, as antocianinas contribuem para o padrão de cores das flores e para a cor roxa intensa de alguns de seus frutos. No maracujá roxo, Pruthi et al. (1961) encontraram pelargonidina 3-diglucosídeo nas cascas dos frutos. Billot (1974) identificou 3,5-diglucosídeos e 3-glucosídeos das agliconas delfinidol, petunidol e malvidol, que ocorrem nas flores de P. quadrangularis.

Em 1997, Kidoy et al. estudaram os pigmentos antociânicos do fruto de $P$. edulis (variedade não especificada) e de $P$. suberosa. Os extratos metanólicos foram purificados em coluna com Amberlite XAD-7, separados em coluna com Sephadex LH-20 e analisados por CLAE. Análises por RMN e EM demonstraram a presença de cianidina 3- glicosídeo (97\%) e cianidina 3-(6'malonilglicosídeo) (2\%) e pelargonidina 3-glucosídeo (1\%) em $P$. edulis (variedade não especificada).

\section{Vitaminas}

Franco (1996) cita a importância do maracujá devido à presença das vitaminas $\mathrm{A}$, tiamina, riboflavina $\mathrm{e}$ C (Tabela 3). Segundo Pruthi (1963), o suco é um dos mais ricos em niacina (vitamina $\mathrm{B} 3$ ). A vitamina $\mathrm{C}$ é talvez a mais investigada por ser um dos principais indicadores do valor nutritivo do suco. A variedade roxa, com 29,80 mg de ácido ascórbico/100 mL de suco em média, apresenta maior teor de vitamina $\mathrm{C}$ que a variedade amarela, que possui 20,0 mg de ácido ascórbico/100 mL de suco (Sepúlveda et al., 1996). Vinci et al. (1995) utilizando CLAE, encontraram valores superiores para o maracujá amarelo fresco, 64,78 mg/100g, o que permite considerar o maracujá como uma fonte adicional de vitamina $\mathrm{C}$ na dieta.

Pruthi (1963) analisou o ácido ascórbico em diferentes partes de $P$. edulis fo. flavicarpa, encontrando maior quantidade nas folhas $(292,5 \mathrm{mg} / 100 \mathrm{~g})$. Entretanto, os mesmos autores reforçam que as variações dependem da idade da planta bem como de outros fatores agronômicos.

Zibadi \& Watson (2004) relatam as vitaminas presentes em $100 \mathrm{~g}$ de suco do fruto do maracujá roxo: riboflavina ou vitamina $\mathrm{B} 2(0,1 \mathrm{mg})$, niacina ou vitamina $\mathrm{B}_{3}(1,50 \mathrm{mg})$, vitamina $\mathrm{B}_{6}(0,1 \mathrm{mg})$, folato ou ácido fólico $(7,0 \mu \mathrm{g})$, vitamina A (717,0 UI), vitamina E $(0,01 \mathrm{mg})$ e vitamina $\mathrm{K}(0,40 \mu \mathrm{g})$.

\section{Substâncias voláteis}

Devido ao seu "flavour" único e delicado, os frutos das espécies do gênero Passiflora têm sido assunto de intensa pesquisa, resultando na caracterização de centenas de constituintes voláteis, alguns presentes somente em baixíssimas concentrações (traços). Apesar disso, sabese que, por efeitos sinergísticos ou antagônicos, essas substâncias são extremamente importantes na composição do aroma do maracujá (Tocchini et al., 1994).

Na época da revisão de Pruthi (1963), somente os constituintes voláteis do maracujá amarelo ( $P$. edulis fo. flavicarpa) tinham sido identificados, dentre eles apenas quatro ésteres. Em 1981, Casimir et al., em extensa revisão, listam mais de sessenta substâncias voláteis já identificados do maracujá roxo e amarelo. Segundo Whitfield \& Last (1986) em meados da década de 80 já haviam sido identificadas aproximadamente trezentas substâncias. Mais tarde, Werkhoff et al. (1998) identificaram 180 novas substâncias no maracujá amarelo, dentre as quais quatorze ainda não haviam sido relatadas como de ocorrência natural no aroma. Utilizando CG capilar multidimensional preparativa, identificaram mais de cem substâncias voláteis contendo enxofre. Entretanto, somente 47 destas substâncias foram identificadas no maracujá amarelo, das quais 35 foram relatadas no "flavour" de uma fruta tropical pela primeira vez e 23 são novas substâncias. A distribuição enantiomérica de muitas substâncias quirais foi determinada por CG multidimensional enantioseletiva.

Os ésteres (alifáticos, aromáticos e terpenoides) são as substâncias voláteis mais abundantes, seguido por norterpenoides $\mathrm{C}_{13}$ e monoterpenoides (Murray et al., 1972; Narain \& Bora, 1992). Como sumarizado por Whitfield \& Last (1986) é a diferença na composição destas três classes de substâncias que diferencia principalmente o "flavour" das formas amarela e roxa.

Narain et al. (2004) analisaram as substâncias voláteis da polpa do maracujá ( $P$. edulis fo. flavicarpa) usando headspace dinâmico e CGAR-EM. Foram identificadas 48 substâncias voláteis: ésteres (59,24\%), aldeídos $(15,27 \%)$, cetonas $(11,70 \%)$ e álcoois $(6,56 \%)$. Carasek \& Pawliszyn (2006) fizeram a extração direta das substâncias voláteis do fruto de maracujá usando microextração em fase sólida por headspace (HS-SPME). Através de CG-EM foram identificadas 42 substâncias no aroma do fruto, a maioria terpenos e ésteres.

Engel \& Tressl (1983a ) concluíram que alguns ésteres típicos da variedade roxa, p. ex., 2-heptila, 2-nonila, (Z)-3-hexenila, geranila, citronelila, além do acetato de (Z)-3-octenila, contribuem para a qualidade do "flavour" do maracujá roxo. Por outro lado, substâncias que contêm enxofre, especialmente 3-metiltiohexanol e 2-metil-4-propil-1,3-oxatiano, são consideradas como os constituintes responsáveis pelo impacto do "flavour" do maracujá amarelo (Winter et al., 1976; Engel \& Tressl, 1991).

Tominaga \& Dubourdieu (2000) relatam dois tióis voláteis (3-mercapto-3-metilbutano-1-ol e acetato 
de 3-mercapto-3-metilbutila), identificados pela primeira vez no suco do maracujá $(P$. edulis, variedade não especificada). Também foi identificado, por CG-EM, o precursor do 3-mercaptohexano-1-ol como S-(3-hexano1-ol)-L-cisteina, que contribuem para o aroma do fruto.

Especial atenção tem sido dada à análise de substâncias quirais nas duas variedades de maracujá (Singer et al., 1986; Bernreuther et al., 1989). Os estudos de Tressl et al. (1985) mostraram diferenças na composição enantiomérica entre as variedades roxa e amarela. Por exemplo, na variedade roxa encontrou-se principalmente o $R(-)$-2-heptanol (92\%), e na variedade amarela o enantiômero $S(-)$ 82\%. Schmidt et al. (1995) sintetizaram os edulanos I e II, componentes importantes do "flavour" do maracujá roxo, cuja distribuição enantiomérica foi estabelecida em extratos e destilados de diversas origens geográficas por meio de um acoplamento on-line multidimensional de CG-EM, constatando-se o predomínio da forma enantiomérica $(2 S)$. Na variedade amarela, o etil-3-hidroxibutanoato é principalmente o enantiômero $S$ $(82 \%)$, e na variedade roxa predomina o enantiômero $R$ $(69 \%)$

Um outro tópico da pesquisa sobre o "flavour" do maracujá tem sido a formação de substâncias de aroma a partir de precursores não voláteis. Engel \& Tressl (1983b) mostraram que no maracujá, em adição aos monoterpenos livres, havia também precursores polares não voláteis, predominantemente glicosídeos de álcoois monoterpênicos, linalol, nerol, geraniol e $\alpha$-terpineol, além de derivados hidroxilados de linalol, os quais poderiam ser transformados em importantes componentes do aroma por reações físico-químicas (Chassagne et al, 1996b).

Finalmente, destaque deve ser dado à importante contribuição de norterpenoides $\mathrm{C}_{13}$ para o "flavour" do maracujá (Winterhalter, 1990; Chassagne et al., 1999). Trinta e dois norterpenoides foram identificados nas variedades roxa e amarela (Whitfield \& Last, 1986; Winterhalter, 1990) incluindo cetonas intensamente odoríferas como a $\beta$-ionona e $\beta$-damascenona (Casimir et al., 1981). Muitos éteres norterpenoides, os chamados edulanos (Murray et al.; 1972; Whitfield et al., 1973; Prestwich et al., 1976; Whitfield \& Stanley, 1977; Whitfield \& Sugowdz, 1979; Winter et al., 1979; Herderich \& Winterhalter, 1991; Schmidt et al., 1995; Demole et al., 1979) e alguns hidrocarbonetos isoméricos, os megastigma4,6,8-trienos, os quais somente ocorrem na variedade roxa, são considerados a chave do "flavour" desta variedade (Murray et al., 1972; Whitfield et al., 1977; Whitfield \& Sugowdz, 1979; Casimir et al., 1981).

As pesquisas realizadas até o momento sobre os constituintes voláteis do maracujá restringem-se praticamente aos frutos. Buchbauer \& Jirovetz (1992) estudaram o óleo essencial das folhas de $P$. incarnata L. por CG, CG-EM e CG-IV, e os principais componentes do óleo descritos foram: hexanal $(1,4 \%)$, álcool benzílico $(4,1 \%)$, linalool $(3,2 \%)$, álcool 2-feniletílico $(1,2 \%)$, éster metílico do ácido 2-hidroxibenzoico (1,3\%), carvona $(8,1 \%)$, trans-anetol $(2,6 \%)$, eugenol $(1,8 \%)$, isoeugenol $(1,6 \%), \quad \beta$-ionona $(2,6 \%), \alpha$-bergamotol $(1,7 \%)$, fitol $(1,9 \%)$ e dois ácidos graxos: palmítico $(7,2 \%)$ e oleico (6,3\%). Mais de 150 componentes minoritários também foram identificados.

\section{Flavonoides}

Os flavonoides encontrados em espécies de Passiflora são principalmente do tipo $C$-glicosídeos, nos quais os açúcares apresentam pouca diversificação, sendo o principal a glucose, e estão diretamente ligados ao núcleo aromático por uma ligação carbono-carbono resistente à hidrólise, apenas nas posições 6 e 8 do núcleo dos flavonoides (Jay, 1996). Os $C$-glicosídeos são menos solúveis em acetato de etila do que as agliconas de flavonas e podem permanecer na fase aquosa após hidrólise. Durante hidrólise ácida, podem sofrer isomerização formando misturas de 8-C-glicosídeos e 6-C-glicosídeos (Markham, 1982).

Os flavonoides apresentam vários efeitos biológicos e farmacológicos, incluindo atividade antibacteriana, antiviral, anti-inflamatória, antialérgica e vasodilatadora. Além disso, estas substâncias inibem a peroxidação lípidica e reduzem o risco de doenças cardiovasculares, efeitos estes relacionados à sua atividade antioxidante, caracterizada pela capacidade de sequestrar radicais livres em organismos vivos (Hollman \& Katan, 1997; Hollman \& Katan, 1999; Havsteen, 1983; Hollman et al., 1996; Cook \& Samman, 1996).

A grande maioria dos trabalhos sobre os flavonoides do maracujá foi realizada em folhas e partes aéreas. Uma revisão destas informações foi realizada por Pereira \& Vilegas (2000) abrangendo a literatura até 1999. Mais recentemente foram relatadas a atividade leishmanicida dos flavonóides de $P$. edulis Sims (variedade não especificada) (Bezerra et al., 2006) e a atividade anticonvulsante dos flavonóides de P. alata (Quintans Junior et al., 2008). Foram relatados poucos trabalhos sobre os frutos: Lutomski et al. (1975) relataram 1,0 $\mathrm{mg} \%$ de flavonoides nas duas variedades de P. edulis, por cromatografia em papel e densitometria.

Mareck et al. (1990) identificaram por CLAE flavonoides $C$-glicosídeos no suco dos frutos do maracujá amarelo e no suco industrializado. Foram encontrados no suco dos frutos frescos os flavonoides: apigenina-6- $C$ glicosil-8- $C$-arabinosídeo (shaftosídeo, 1) em mistura com apigenina-6-arabinosil-8-C-glicosídeo (isoshaftosídeo, 2), isoorientina (3), orientina (4), isovitexina (5), luteolina 6- $C$-quinovosídeo (6) e luteolina 6- $C$-fucosídeo (7). No suco industrializado foi relatada a presença de (1), (3), (4) e (5). 
<smiles>[R]c1ccc(-c2cc(=O)c3c(O)c([R3])c(O)c([R])c3o2)cc1[R]</smiles>

\begin{tabular}{lcccc}
\hline \multicolumn{1}{c}{ Flavonoides } & $\mathrm{R}_{1}$ & $\mathrm{R}_{2}$ & $\mathrm{R}_{3}$ & $\mathrm{R}_{4}$ \\
\hline (1) Shaftosídeo & $\mathrm{OH}$ & $\mathrm{H}$ & glucose & arabinose \\
(2) Isoshaftosídeo & $\mathrm{OH}$ & $\mathrm{H}$ & arabinose & glucose \\
(3) Isoorientina & $\mathrm{OH}$ & $\mathrm{OH}$ & glucose & $\mathrm{H}$ \\
(4) Orientina & $\mathrm{OH}$ & $\mathrm{OH}$ & $\mathrm{H}$ & glucose \\
(5) Isovitexina & $\mathrm{OH}$ & $\mathrm{H}$ & glucose & $\mathrm{H}$ \\
(6) Luteolina 6- $C$-quinovosídeo & $\mathrm{OH}$ & $\mathrm{OH}$ & quinose & $\mathrm{H}$ \\
(7) Luteolina 6- $C$-fucosídeo & $\mathrm{OH}$ & $\mathrm{OH}$ & fucose & $\mathrm{H}$ \\
\hline & & & &
\end{tabular}

Zeraik \& Yariwake (2010) identificaram por CL-EM/EM os flavonoides: isoorientina e isovitexina, além disso, desenvolveram e validaram métodos para quantificação de isoorientina e flavonoides totais na polpa de $P$. edulis f. flavicarpa por CLAE-UV/DAD.

Zucolotto (2005) relatou a presença de flavonoides $C$-glicosídeos no pericarpo, mesocarpo e na casca dos frutos maduros de $P$. edulis f. flavicarpa, flavonoides com comportamento cromatográfico (CCD) semelhantes a (3) e (4).

Os flavonoides relatados nas cascas do maracujá roxo também foram descritos. Ichimura et al. (2006) analisaram por CL-EM/EM as cascas de $P$. edulis (variedade não especificada), encontrando os flavonoides luteolina (8) $(20,0 \mu \mathrm{g} / \mathrm{g})$ e luteolina-6-C-glicosídeo ou isoorientina (3) $(20,0 \mu \mathrm{g} / \mathrm{g})$, além do ácido $\gamma$-aminobutírico (GABA, 2,4 mg/g). Zibadi et al. (2007) relataram que os três principais constituintes da casca do maracujá roxo são: cianidina 3-O-glicosídeo, quercetina 3-O-glicosídeo (9) e ácido edulílico. Substâncias minoritárias encontradas $(<1 \%)$ foram: catequina, epicatequina, kaempferol 3-O-glicosídeo (10), kaempferol (11), luteolina-8- $C$ neohesperosídeo (12), luteolina-8-C-digitoxosidio (13), ácido protocatéquico, quercetina (14) e prunasina. As análises foram realizadas por CLAE-UV/DAD.<smiles>[R]c1ccc(-c2oc3c([R])c(O)c([R3])c(O)c3c(=O)c2[R])cc1O</smiles>

\begin{tabular}{|c|c|c|c|c|}
\hline Flavonoides & $\mathrm{R}_{1}$ & $\mathrm{R}_{2}$ & $\mathrm{R}_{3}$ & $\mathrm{R}_{4}$ \\
\hline (8) Luteolina & $\mathrm{OH}$ & $\mathrm{H}$ & $\mathrm{H}$ & $\mathrm{H}$ \\
\hline $\begin{array}{l}\text { (9) Quercetina 3-O- } \\
\text { glicosídeo }\end{array}$ & $\mathrm{OH}$ & $O$-glucose & $\mathrm{H}$ & $\mathrm{H}$ \\
\hline $\begin{array}{l}\text { (10) Kaempferol 3-O- } \\
\text { glicosídeo }\end{array}$ & $\mathrm{H}$ & $O$-glucose & $\mathrm{H}$ & $\mathrm{H}$ \\
\hline (11) Kaempferol & $\mathrm{H}$ & $\mathrm{OH}$ & $\mathrm{H}$ & $\mathrm{H}$ \\
\hline $\begin{array}{l}\text { (12) Luteolina 8-C- } \\
\text { neohesperosídeo }\end{array}$ & $\mathrm{OH}$ & $\mathrm{H}$ & $\mathrm{H}$ & neohesperosideo \\
\hline $\begin{array}{l}\text { (13) Luteolina 8-C- } \\
\text { digitoxosídeo }\end{array}$ & $\mathrm{OH}$ & $\mathrm{H}$ & $\mathrm{H}$ & digitoxosídeo \\
\hline (14) Quercetina & $\mathrm{OH}$ & $\mathrm{OH}$ & $\mathrm{H}$ & $\mathrm{H}$ \\
\hline
\end{tabular}

Alcaloides

Os alcaloides presentes em Passiflora são do tipo indólico. Os alcaloides indólicos compreendem o segundo grande grupo de alcaloides atualmente conhecidos. Muitos têm valor na medicina como tranquilizantes e no tratamento da hipertensão (Harborne \& Baxter, 1995).

Lutomski \& Malek (1975) estudaram P. edulis Sims (variedade não especificada) e compararam o teor de alcaloides harmânicos nos diferentes órgãos vegetais, verificando que o maior teor ocorre nas folhas. Em P. edulis fo. Alavicarpa foi verificada a presença de alcaloides (expressos em harmana) em todas as partes, exceto nas raízes (Lutomski \& Malek, 1976).

Apesar do grande uso popular do suco de $P$. edulis fo. flavicarpa no combate à ansiedade, depressão e insônia, apenas um trabalho relatou a presença de alcaloides responsáveis por este efeito calmante atribuído ao suco. Lutmoski et al. (1975) investigaram o conteúdo de alcaloides no suco de $P$. edulis fo. edulis $(0,012 \mathrm{mg} \%)$ e em P. edulis fo. Alavicarpa $(0,7 \mathrm{mg} \%)$, utilizando cromatografia em papel, densitometria e identificaram os alcaloides harmana (15), harmina (16), harmol (17) e harmalina (18), utilizando o reagente de Dragendorff (que pode fornecer resultados falso-positivos). Por isso, ainda são necessários estudos com técnicas mais apuradas para confirmação destas substâncias no suco.<smiles>[R]c1ccc2c(c1)[nH]c1c(C)nccc12</smiles>

15 harmana, $\mathrm{R}=\mathrm{H}$

16 harmina, $\mathrm{R}=\mathrm{OCH}_{3}$ 17 harmol, $\mathrm{R}=\mathrm{OH}$<smiles>COc1ccc2c3c([nH]c2c1)C(C)=NCC3</smiles>

18 harmalina
Dhawan et al. (2004) citam em sua revisão que alcaloides $\beta$-carbolínicos presentesnas folhasde P. incarnata foram determinados quantitativamente por CLAE com detector de fluorescência. Uma explicação para os valores discrepantes encontrados da literatura (Dhawan et al., 2004) deve-se em parte às metodologias aplicadas na quantificação 
destas substâncias. Além disso, pode-se considerar como fatores de variação do teor alcaloídico em drogas vegetais: os órgãos empregados, a época e o local de colheita.

\section{CONSIDERAÇÕES FINAIS}

Esta revisão torna evidente que ainda são necessários mais estudos sobre os constituintes químicos das diversas partes dos frutos do maracujá, principalmente de $P$. alata, espécie oficial da Farmacopeia Brasileira.

Muitas substâncias presentes nos frutos, principalmente na polpa e casca, podem contribuir para efeitos benéficos, tais como: atividade antioxidante, antihipertensão, diminuição da taxa de glicose e colesterol do sangue. As variedades comerciais de maracujá são também ricas em alcaloides, flavonoides, carotenoides, minerais e vitaminas A e C, substâncias responsáveis pelo efeito funcional em outros alimentos. Apesar do grande potencial do maracujá como alimento funcional, ainda são poucos os estudos existentes com este enfoque sobre os frutos das espécies utilizadas em alimentação no Brasil.

Observou-se também que os subprodutos (cascas e sementes) são passíveis de serem aproveitados, e, além disso, apresentam ações farmacológicas ou interesse nutricional; a casca é rica em pectina, além de outras substâncias como os flavonoides e as sementes são ricas em ácidos poliinsaturados como os $\omega-3$ e $\omega-6$.

\section{AGRADECIMENTOS}

Os autores agradecem à FAPESP pelo apoio financeiro e ao CNPq e à CAPES pelas bolsas concedidas.

\section{REFERÊNCIAS}

Angelis RC 2001. New concepts in nutrition: considerations on the connection diet-health. Arq Gastroenterol 38: 269-271.

Agra MF, Freitas PF, Barbosa-Filho JM 2007. Synopsis of the plants known as medicinal and poisonous in Northeast of Brazil. Rev Bras Farmacogn 17: 114-140.

Anjo DFC 2004. Alimentos funcionais em angiologia e cirurgia vascular. $J$ Vasc $B r$ 3: 145-154.

Araújo CL, Bezerra IWL, Dantas IC, Lima TVS, Oliveira AS, Miranda MRA, Leite EL, Sales MP 2004. Biological activity of proteins from pulps of tropical fruits. Food Chem 85: 107-110.

Araujo L 2005. Sistema brasileiro de resposta técnica. Brasília: CETEC.

Barbosa-Filho JM, Alencar AA, Nunes XP, Tomaz ACA, SenaFilho JG, Athayde-Filho PF, Silva MS, Souza, MFV, Leitão da Cunha, EV 2008. Sources of alpha-, beta-, gamma-, delta- and epsilon-carotenes: a twentieth century review. Rev Bras Farmacogn 18: 135-154.

Bernreuther A, Christoph N, Schreier P 1989. Determination of the enantiomeric composition of $\gamma$-lactones in complex natural matrices using multidimensional capillary gas chromatography. $J$ Chromatogr 481: 363-367.

Bezerra JL, Costa GC, Lopes TC, Carvalho ICDS, Patricio FJ, Sousa SM, Amaral FMM, Rebelo JMM, Guerra
RNM, Ribeiro MNS, Nascimento FRF 2006. Avaliação da atividade leishmanicida in vitro de plantas medicinais. Rev Bras Farmacogn 16: 631-637.

Billot J 1974. Pigments anthocyaniques des fleurs de Passiflora quadrangularis. Phytochemistry 13: 2886-2886.

Buchbauer G, Jirovetz L 1992. Volatile constituents of the essential oil of Passiflora incarnata L. J Essent Oil Res 4: 329-334.

Carasek E, Pawliszyn J 2006. Screening of tropical fruit volatile compounds using solid-phase microextraction (SPME) fibers and internally cooled SPME fiber. J Agric Food Chem 54: 8688-8696.

Carvalho-Okano RM, Vieira MF, Bruckner CH, Picanço MC 2001. Maracujá. Tecnologia de produção, pós-colheita, agroindústria, mercado. Porto Alegre: Cinco Continentes, p. 33.

Casimir DJ, Kefford JF, Whitfield FB 1981. Technology and flavour chemistry of passion fruit juices and concentrates. Adv Food Res 27: 243-295.

Cati 1992. Pragas e doenças do maracujá. Campinas: SAA/CATI. Chan HT, Chang TSK, Chenchin E 1972. Nonvolatile acids of passionfruit juice. J Agric Food Chem 20: 110-112.

Chan HT, Kwok SMC 1975. Identification and determination of sugarsinsome tropicalfruitproducts.JFood Sci 40:419-420.

ChassagneD, BoulangerR, CrouzetJ1999. Enzymatichydrolysis of edible Passiflora fruit glycosides. Food Chem 66:281-288.

Chassagne D, Crouzet J, Bayonove CL, Baumes RL 1996a. Identification and quantification of passion fruit cyanogenic glycosides.J Agric Food Chem 44:3817-3820.

Chassagne D, Crouzet J, Bayonove CL, Brillouet JM, Baumes RL 1996b. 6-o- $\alpha$-L-arabinopyranosyl$\beta$-D-glucopyranosides as aroma precursors from passion fruit. Phytochemistry 41: 1497-1500.

Chassagne D, Crouzet J 1998. A cyanogenic glycoside from Passiflora edulis fruits. Phytochemistry 49: 757-759.

Chau CF, Huang YL 2004. Characterization of passion fruit seed fibres - a potential fibre source. Food Chem 85: 189-194.

Chau CF, Huang YL 2005. Effects of the insoluble fiber derived from Passiflora edulis seed on plasma and hepatic lipids and fecal output. Mol Nutr Food Res 49: 786-790.

Cook NC, Samman S 1996. Flavonoids-chemistry, metabolism, cardioprotective effects, and dietary sources. Nutr Biochem 7: 66-76.

Córdova KRV, Gama TMMTB, Winter CMG, Neto GK, Freitas RJS 2005. Características físico-químicas da casca do maracujá amarelo (Passiflora edulis flavicarpa Degener) obtida por secagem. Bol Cent Pesq Proc Alim 23: 221-230.

Costa AM, Tupinambá DD 2005. O maracujá e suas propriedades medicinais estado de arte. In: Faleiro FG, Junqueira NTV, Braga MF (Ed.). Maracujá: germoplasma e melhoramento genético. Planaltina: Embrapa Cerrados, cap. 20, p. 475-506. Culhane C 1995. Nutraceuticals/Functional Foods an exploratory survey on Canada's potential. Toronto: International Food Focus Limited.

Demole E, Enggist P, Winter M, Furrer A, Schulte-Elte KH, Egger B, Ohloff G 1979. Megastigma-5,8-dien-4one, an aroma constituent of the yellow passion fruit and Virginia tobacco. Helv Chim Acta 62: 67-75.

Dhawan K, Dhawan S, Sharma A 2004. Passiflora: a review update. $J$ Ethnopharmacol 94: 1-23.

Engel KH, Tressl R 1983a. Differentiation of yellow and purple passion fruits by investigation of their ester composition. Chem Mikrobiol Technol Lebensm 8: 33-39.

Engel KH, Tressl R 1983b. Formation of aroma 
components from nonvolatile precursors in passion fruit. J Agric Food Chem 31: 998-1002.

Engel KH, Tressl R 1991. Identification of new sulfur-containing volatiles in yellow passion fruits (Passiflora eduls f. Alavicarpa). J Agric Food Chem 39: 2249-2252.

European Pharmacopoeia. Strasbourg: Council of Europe, 1996. Farmacopéia Brasileira. São Paulo: Atheneu Editora São Paulo, 1977.

Ferrari RA, Colussi F, Ayub RA 2004. Characterization of by-products of passion fruit industrialization utilization of seeds. Rev Bras Frutic 26: 101-102.

Ferreira RQ, Avaca LA 2008. Electrochemical determination of the antioxidant capacity: the ceric reducing/antioxidant capacity (CRAC) assay. Electroanal 20: 1323-1329.

Franco LL 1996. As sensacionais 50 plantas medicinais - campeãs de poder curativo, Curitiba: Editora Santa Mônica.

Giuffré AM 2007. Chemical composition of purple passion fruit (Passiflora edulis var. Sims edulis) seed oil. Riv Ital Sost Grasse 84: 87-93.

Gioria R, Bosque GG, Rezende JAM, Amorim L, Kitajima EW 2000. Incidência de viroses de maracujazeiro na Alta Paulista- SP e danos causados pelo Passion fruit woodiness virus. Fitopatol Bras 25: 182-189.

Godoy HT, Rodriguez-Amaya DB $1994 . \quad$ Occurrence of cis-isomers of provitamin A in Brazilian fruits. $J$ Agric Food Chem 42: 1306-1313.

Gondim JAM, Moura MFV, Dantas AS, Medeiros RLS, Santos KM. 2005. Composição centesimal e de minerais em cascas de frutas. Cien Tecnol Aliment 25: 825-827.

Guertzenstein SMJ 1998. Uso da casca de maracujá (Passiflora edulis $f$. flavicarpa, Deg) cv. amarelo com fonte de fibra solúvel na alimentação de ratos dabéticos. Rio de Janeiro, 116p. Dissertação de Mestrado - Mestrado em Nutrição, Universidade Federal do Rio de Janeiro.

Guertzenstein SMJ, Sabaa-Srur AUO 1999. Uso da casca do maracujá (Passiflora edulis f. flavicarpa Deg.) cv amarelo como fonte de fibra na alimentação de ratos (Rattus norvegicus) nomais e diabéticos. Anais do III Simpósio Latino Americano de Ciência de Alimentos. Campinas, Brasil.

Haard NF, Chism GW 1996. Characteristics of edible plant tissues. In: Fennema O (ed.) Food Chemistry. New York: Marcel Dekker Inc., p. 944-966.

Harborne JB, Baxter H 1995. Phytochemical Dictionary: A Handbook of Bioactive Compounds from Plants, London: Taylor e Francis.

Havsteen B 1983. Flavonoids, a class of natural products of high pharmacological potency. Biochem Pharm 32: 1141-1148.

Heim KE, Tagliaferro AR, Bobilya DJ 2002. Flavonoid antioxidants: chemistry, metabolism and structureactivity relationships. $J$ Nutr Biochem 13: 572-584.

Herderich M, Winterhalter P 1991.3-Hydroxy-retro-alpha-ionol: a natural precursor of isomeric edulans in purple passion fruit (Passifloraedulis Sims).JAgricFoodChem 39:1270-1274.

Hollman PCH, Hertog MGL, Katan MB 1996. Analysis and health effects of flavonoids. Food Chem 57: 43-46.

Hollman PCH, Katan MB 1997. Absorption, metabolism and health effects of dietary flavonoids in man. Biomed Pharmacother 51: 305-310.

Hollman PC, Katan MB 1999. Dietary flavonoids: intake, health effectsandbioavailability. FoodChem Toxicol37:937-942.

Ichimura T, Yamanaka A, Ichiba T, Toyokawa T, Kamada Y, Tamamura T, Maruyama S 2006. Antihypertensive effect of an extract of Passiflora edulis rind in spontaneously hypertensive rats. Biosci Biotechnol Biochem 70: 718-721.

IBGE 2007. Produção agrícola municipal. http://www.ibge.gov. br/home/estatistica/economia/pam/2007/comentario.pdf.

Inomata EI, Sabino M, Pregnolatto W, Concillio MS 1983. Determinação do teor de suco de maracujá em produtos industrializados. Rev Inst Adolfo Lutz 43: 9-14.

Instituto de Tecnologia de Alimentos 1994. Maracujá: cultura, matéria-prima, processamento e aspectos econômicos. Campinas: ITAL.

Jay M 1996. C-glycosylflavonoids. In: Harborne, J.B. (ed.) The Flavonoids - Advances in Research Since 1986. London: Chapman Hall, p. 64

Kidoy L, Nygard AM, Andersen OM, Pedersen AT, Aksnes DW, Kiremire BT 1997. Anthocyanins in fruits of Passiflora edulis and P. suberosa. J Food Compos Anal 10: 49-54.

Kobori CN, Jorge N 2005. Caracterização dos óleos de algumas sementes de frutas como aproveitamento de resíduos industriais. Cien Agrotec 29: 1008 - 1014.

Kuskoski EM, Asuero AG, Morales MT, Fett R 2006. Frutos tropicais silvestres e polpas de frutas congeladas: atividade antioxidante, polifenóis e antocianinas. Cien Rural 36: 1283-1287.

Kuskoski EM, Asuero AG, Troncoso AM, Mancini-Filho J, Fett R 2005. Aplicación de diversos métodos químicos para determinar actividad antioxidante en pulpa de frutos. Cien Tecnol Aliment 25: 726-732.

Lajolo FM 2001. Alimentos Funcionais. Rev Racine 11: 18-24.

Leonel S, Leonel M, Duarte-Filho J 2000. Principais produtos e subprodutos obtidos do maracujazeiro. Informe Agropecuário 21: 86-88.

Leuenberger FJ, Thommen H 1972. The occurrence of carotenoids in passion fruit. Z Lebensm Unters Forsch 149: 279-282.

Lutomski J, Malek B 1976. Phytochemical studies of drugs from Passiflora edulis Sims. flavicarpa. Herba Hung 15: 7-11.

Lutomski J, Malek B 1975. Pharmakochemische undersuchungen von drogen der gattung Passiflora L. 3. Mitteilung: Phytochmische forschung der drogen aus Passiflora edulis Sims. forma flavicarpa. Planta Med 27: 222-225.

Lutomski J, Malek B, Rybacka L 1975. Pharmacochemical investigation of the raw materials from Passiflora genus. 2. The pharmacochemical estimation of juices from the fruits of Passiflora edulis and Passiflora edulis forma flavicarpa. Planta Med 27: 112-121.

Mareck U, Galensa R, Herrmann K 1990. Identifizierung von Passionsfruchtsaft in Fruchtprodukten mittels HPLC. Z Lebensm Unters Forsch 191: 269-274.

Markham KR 1982. Techniques of flavonoid identification. New York: Academic Press.

Marliére, LDP, Ribeiro AQ, Brandão MGL, Klein CH, Acurcio FA 2008. Utilização de fitoterápicos por idosos: resultados de um inquérito domiciliar em Belo Horizonte (MG), Brasil. Rev Bras Farmacogn 18: 754-760.

Martin CA, Almeida VV, Ruizi MR, Visentainer JEL, Matshushita M, Souza NE, Visentainer JV 2006. Ácidos graxos poliinsaturados ômega-3 e ômega-6: importância e ocorrência em alimentos. Rev Nutr 19: 761-770.

Meletti LMM, Maia ML 1999. Maracujá: produção e comercialização. Campinas: IAC. Meletti LMM 1996. Maracujá: produção e comercialização em São Paulo. Campinas: IAC. Mercadante AZ, Britton G, Rodriguez-Amaya DB 1998. Carotenoids from yellow passion fruit (Passiflora 
edulis). J Agric Food Chem 46: 4102-4106.

MinistériodaAgricultura2010.http://www.agricultura.gov.br/pls/ portal/docs/PAGE/MAPA/SERVICOS/PROTECAO INTEGRADA DE FRUTAS1/PROD INTEGRADA NORMAS TECNICAS $2 /$ GRADE\%20PI\% 20 CITROS\%2031-01-10_0.PD. Acessd em maio 2010.

Moraes FP, Colla LM 2006. Alimentos funcionais e nutracêuticos: definições, legislação e benefícios à saúde. Rev Eletr Farm 3: 109-122.

MortonJ1987.Passionfruit.http://www.hort.purdue.edu/newcrop/ morton/Passionfruit.html, acessada em Dezembro 2008.

Murray KE, Shipton J, Whitfield FB 1972. The chemistry of food "flavour". I. Volatile constituents of passion fruit., Passiflora edulis. Austr J Chem 25: 1921-1933.

Narain N, Almeida JN, Galvão MS, Madruga MS, Brito ES 2004. Compostos voláteis dos frutos de maracujá (Passiflora edulis forma flavicarpa) e de cajá (Spondias monbin L.) obtidos pela técnica de headspace dinâmico. Cien Tecnol Aliment 24: 212-216.

Narain N, Bora PS 1992. Post-harvest changes in some volatile flavour constituents of yellow passion fruit (Passiflora edulis f. Alavicarpa). J Sci Food Agric 60: 529-530.

Oliveira LF, Nascimento MRF, Borges SV, Ribeiro PCN, Ruback VR2002.Aproveitamentoalternativodacascadomaracujáamarelo (Passiflora edulis F. Flavicarpa) para produção de doce em calda. Cien Tecnol Aliment 22: 259-262.

Otagaki KK, Matsumoto H 1958. Nutritive values and utility of passion fruit by products. J Agric Food Chem 6: 54-57.

PaivaR1998.Leitecommaracujá.Titulo.RevGloboRural152:9-15.

Pereira CAM, Vilegas JHY 2000. Constituintes químicos e farmacologia do gênero Passiflora com ênfase a $P$. alata, $P$. edulis e $P$. incarnata: revisão da literatura. Rev Bras Med 3: 1-12.

Pinheiro AM, Fernandes AG, Fai AEC, do Prado GM, de Sousa PHM, Maia GA 2006. Avaliação química, físico-química e microbiológica de sucos de frutas integrais: abacaxi, caju e maracujá. Cien Tecnol Aliment 26: 98 - 103.

Piombo G, Barouh N, Barea B, Boulanger R, Brat P, Pina M, Villeneuve $\mathrm{P} 2006$. Characterization of the seed oils from kiwi(Actinidia chinensis), passion fruit (Passiflora edulis) andguava(Psidiumguajava).OlCorps GrasLi13:195-199.

Prestwich GD, Whitfield FB, Stanley G 1976. Synthesis and structures of dihydroedulan I II trace components from the juice of Passifloraedulis Sims. Tetrahedron 32:2945-2948.

Pruthi JS 1963. Physiology, chemistry, and technology of passion fruit. Adv Food Res 12: 203-282.

Pruthi JS, Susheela R, Lal G 1961. Anthocyanin pigment in passion fruit rind. $J$ Food Sci 26: 385-388.

Puricelli L, Dell'Aica I, Sartor L 2003. Preliminary evaluation of inhibition of matrix-metalloprotease MMP-2 and MMP-9 by Passiflora edulis and $P$. foetida aqueous extracts. Fitoterapia 74: 302-304.

Quintans Junior LJ, Almeida JRGS, Lima JT, Nunes XP, Siqueira JS, Oliveira LEG, Almeida RN, Athayde-Filho PF, Barbosa-Filho, JM 2008. Plants with anticonvulsant properties - a review. Rev Bras Farmacogn 18: 798-819.

Ramos AT, Cunha MAL, Sabaa-Srur AUO, Pires VCF, Cardoso MAA, Diniz MFM, Medeiros CCM 2007. Uso de Passiflora edulis flavicarpa na redução do colesterol. Rev Bras Farmacogn 17: 592-597.

Ramos ERF 2004. O uso de Passiflora spp. no controle do Diabetes mellitus: estudo qualitativo preliminar. Maringá, 36p. Monografia de Conclusão de Curso de Farmácia, Centro Universitário de Maringá. Ribeiro AQ, Leite JPV, Dantas-Barros AM 2005. Perfil de utilização de fitoterápicos em farmácias comunitárias de Belo Horizonte sob a influência da legislação nacional. Rev Bras Farmacogn 15: 65-70.

Robbers JE, Spudie MK, Tyler VE 1996. Pharmacognosy and pharmacobiotechnology, Baltimore: Williams e Wilkins.

Roberfroid MB 2002. Functional food concept and its application to prebiotics. Digest Liver Dis 34: 105-110.

Romero-Rodriguez MA, Vazquez-Oderiz ML, LopezHernandez J, Simal-Lozano J 1994. Composition of babaco, feijoa, passion-fruit and tamarillo produced in Galicia (NW Spain). Food Chem 49: 23-27.

Ruggiero C 1987. Cultura do maracujazeiro. Ribeirão Preto: Legis Summa.

Sampaio AC, Scudeller N, Fumis TF, Almeida AM, Pinotti RN, Garcia MJM, Pallamin ML 2008. Manejo cultural do maracujazeiro-amarelo em ciclo anual visando à convivência com o vírus do endurecimento dos frutos: um estudo de caso. Rev Bras Frutic 30: 343-347.

Schieber A, Stintzing FC, Carle R 2001. By-products of plant food processing as a source of functional compounds - recent developments. Trends Food Sci Technol 12: 401-413.

Schmidt G, Full G, Winterhalter P, Schreier P 1995. Synthesis and enantiodifferentiation of isomeric 3,5,6,8atetrahydro-2,5,5,8a-tetramethyl-2H-1-benzopyrans (edulans I and II). J Agric Food Chem 43: 185-188.

Schweizer TF, Wursch P 1991. The physiological and nutritional importance of dietary fiber. Experientia 47: 181-186.

Sepúlveda E, Sáenz C, Navarrete A, Rustom A 1996. Parámetros de color del jugo de granadilla (Passiflora edulis Sims): influencia de la época de cosecha de la fruta. Food Sci Technol Intern 2: 29-33.

Silva MIG, Gondim APS, Nunes IFS, Sousa FCF 2006. Utilização de fitoterápicos nas unidades básicas de atenção à saúde da família no município de Maracanaú (CE). Rev Bras Farmacogn 16: 455-462.

Singer G, Heusinger G, Fröhlich O, Schreier P, Mosandl A 1986. Chirality evaluation of 2-methyl-4propyl-1,3-oxathiane from the yellow passion fruit. J Agric Food Chem 34: 1029-1033.

Sousa FCF, Melo CTV, Citó MCO, Félix FHC, Vasconcelos SMM, Fonteles MMF, Barbosa-Filho JM, Viana GSB 2008. Plantas medicinais e seus constituintes bioativos: uma revisão da bioatividade e potenciais benefícios nos distúrbios da ansiedade em modelos animais. Rev Bras Farmacogn 18: 642-654.

Spencer KC, Seigler DS 1983. Cyanogenesis of Passiflora edulis. J Agric Food Chem 31: 794-796.

Spencer KC, Seigler DS, Nahrstedt A 1986. Linamarin, lotaustralin, linustatin and neolinustatin from Passiflora species. Phytochemistry 25: 645-647.

Tocchini RP, Nisida ALAC, Hashizume T, Medina JC, Turatti JM 1994. III. Processamento: Produtos, caracterização e utilização. In: ITAL (Org.) Maracujá - Cultura, matéria-prima, processamento e aspectos econômicos. Campinas: ITAL, p. 161-164.

Togashi CK, Fonseca JB, Soares RTRN, Gaspar A, Detmann E 2007. Composição em ácidos graxos dos tecidos de frangos de corte alimentados com subprodutos de maracujá. Rev Bras Zootec 36: 2063-2068.

Tominaga T, Dubourdieu D 2000. Identification of cysteinylated aroma precursors of certain volatile thiols in passion 
fruit juice. J Agric Food Chem 48: 2874-2876.

Tressl R, Engel KH, Albrecht W, Abdullah HB 1985. Analysis of chiral aroma components in trace amounts. In: Bills, D.D, Mussinan, C.J. (eds.) Characterization and measurement of flavor compounds. ACS symposium series 289, Washington: American Chemical Society, p. 54-59.

Turano W, Louzada SRN, Derevi SCN, Mendez MHM 2002. Estimativa de consumo diário de fibra alimentar na população adulta, em regiões metropolitanas do Brasil. Nutr Bras 3: 130-135.

Vasco C, Ruales J, Kamal-Eldin A 2008. Total phenolic compounds and antioxidant capacities of major fruits from Ecuador. Food Chem 111: 816-823.

Vinci G, Botrè F, Mele G, Ruggieri G 1995. Ascorbic acid in exotic fruits: a liquid chromatographic investigation. Food Chem 53: 211-214.

Von Elbe JH, Schwartz SJ 1996. Colorants. In: Fennema O. (ed.) FoodChemistry,NewYork:MarcelDekkerInc.,p.674-681.

Watson RR, Zibadi R, Rafatpanah H, Jabbari F, Ghasemi R, Ghafari J, Afrasiabi H, Foo LY, Faridhosseini R 2008. Oral administration of the purple passion fruit peel extract reduces wheeze and cough and improves shortness of breath in adults with asthma. Nutr Res 28: 166-171.

Werkhoff P, Guentert M, Krammer G, Sommer H, Kaulen $\mathrm{J}$ 1998. Vacuum headspace method in aroma research: flavor chemistry of yellow passion fruits. $J$ Agric Food Chem 46: 1076-1093.

Whitfield FB, Last JH 1986. The flavour of the passionfruit - a review. In: Brunke, E.J. (ed.) Progress in essential oil research. Berlin: Walter de Gruyter e Co. p.3-48.

Whitfield FB, Stanley G 1977. The structure and stereochemistry of edulan I and II and the stereochemistry of the 2,5,5,8a-tetramethyl-3,4,4a,5,6,7,8,8a-octahydro2H-1-benzopyrans. Austr J Chem 30: 1073-1091.

Whitfield FB, Stanley G, Murray KE 1973. Concerning the structures of edulan I e II. Tetrahedron Lett 2: 95-98.

Whitfield FB, Sugowdz G 1979. The 6-(but-2'enylidene)-1,5,5,-trimethylcyclohex-1-enes: Important volatile constituents of the juice of the purple passion fruit. Austr J Chem 32: 891-903.

Whitfield FB, Sugowdz G, Casimir DJ 1977. (6E, 2'E) and (6Z, 2'E)-6-(but-2'-enylidene)-1, 5,5,trimethylcyclohex-1-ene: important volatile constituents of the juice of the purple passion fruit (Passiflora edulis Sims.). Chem Ind 12: 502-503.

Winter M, Furrer A, Willhalm B, Thommen W 1976. Identification and synthesis of two new organic sulfur compounds from the yellow passion fruit (Passiflora edulis f. Alavicarpa). Helv Chim Acta 59: 1613-1620.

Winter M, Schulte-Elte KH, Velluz,A, Limacher J, Pickenhagen W, Ohloff G 1979. Aroma constituents of the purple passion fruit. Two new edulan derivatives. Helv Chim Acta 62: 131-134.

Winterhalter P 1990. Bound terpenoids in the juice of the purple passion fruit (Passiflora edulis Sims). J Agric Food Chem 38: 452-455.

Yapo BD, Koffi KLK 2006. Yellow passion fruit rind a potential source of low-methoxyl pectin. $J$ Agric Food Chem 54: 2738-2744.

Zeraik ML, Lira TO, Vieira AE, Yariwake JH 2008. Comparação da capacidade antioxidante do suco de maracujá (Passiflora edulis f. flavicarpa Degener), da garapa (Saccharum officinarum L.) e do chá-mate (Ilex paraguariensis).
Resumos da 31 a Reunião Anual da Sociedade Brasileira de Química, Águas de Lindóia, Brasil.

Zeraik ML, Yariwake, JH 2010. Quantification of isoorientin and total flavonoids in Passiflora edulis fruit pulp by HPLC-UV/DAD. Microchem $\mathrm{J}$, in press, doi:10.1016/j.microc.2010.02.003.

Zibadi S, Farid R, Moriguchi S, Lu Y, Foo LY, Tehrani PM, Ulreich JB, Watson RR 2007. Oral administration of purple passion fruit peel extract attenuates blood pressure in female spontaneously hypertensive rats and humans. Nutr Res 27: 408 -416.

Zibadi S, Watson RR 2004. Passion fruit (Passiflora edulis): composition, efficacy and safety (Review). Evid Based Integrative Med 3: 183-187.

Zucolotto SM 2005. Estudo fitoquímico das folhas, frutos e raízes de P. edulis forma flavicarpa Degener. Florianópolis, 127p. Dissertação de Mestrado - Programa de Pós-graduação em Farmácia, Universidade Federal de Santa Catarina.

Zuin VG, Yariwake JH, Bicchi C 2003. Fast supercritical fluid extraction and high-resolution gas chromatography with electron-capture and flame photometric detection for multiresidue screening of organochlorine and organophosphorus pesticides in Brazil's medicinal plants. J Chromatogr A 985: 159-166. 